\title{
Traduire
}

Ine autre perspective sur $r$ tadadciction

Revue française de la traduction

$240 \mid 2019$

Quand la politique s'en mêle

\section{Lu pour vous : Tarjuman. Enquête sur une trahison française de Brice Andlauer et Quentin Müller}

\section{Agnès Debarge}

\section{(2) OpenEdition}

Journals

Édition électronique

URL : http://journals.openedition.org/traduire/1708

DOI : 10.4000/traduire.1708

ISSN : 2272-9992

Éditeur

Société française des traducteurs

Édition imprimée

Date de publication : 20 juin 2019

Pagination : 80-83

ISSN : 0395-773X

\section{Référence électronique}

Agnès Debarge, «Lu pour vous : Tarjuman. Enquête sur une trahison française de Brice Andlauer et Quentin Müller », Traduire [En ligne], 240 | 2019, mis en ligne le 20 juin 2019, consulté le 23 septembre 2020. URL : http://journals.openedition.org/traduire/1708 ; DOI : https://doi.org/10.4000/traduire. 1708 


\section{Lu pour vous}

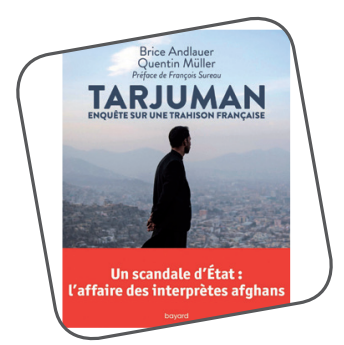

\section{Tarjuman. Enquête sur une trahison française de Brice Andlauer et Quentin Müller}

\section{Agnès Debarge}

Nous considérons toute personne protégeant ou soutenant les étrangers en tant qu'interprète comme un traître, à notre cause et à celle du peuple afghan. Tout comme les soldats ou autres occupants étrangers, ils seront mis à mort'1.

Tarjuman signifie interprète en dari, l'une des langues parlées en Afghanistan; sa proximité phonologique avec le terme «truchement» nous est précisée par le Dictionnaire historique de la langue française ${ }^{2}$. Mais point d'étymologie ici: il est question des interprètes qui ont travaillé pour l'armée française dans ce pays, des interprètes qui ont apporté leur assistance linguistique, et plus, aux troupes déployées dans le pays. Le sous-titre de l'ouvrage, Enquête sur une trahison française, renvoie au sort qu'ont connu ces PCRL (personnel civil de recrutement local) lorsque les troupes ont commencé à opérer leur retrait. Avec minutie, les deux jeunes journalistes Brice Andlaver et Quentin Müller décrivent, creusent, fouillent, analysent et narrent avec toute l'humanité qui s'impose les parcours de jeunes hommes désireux 
de contribuer à libérer leur pays des talibans, qui furent par la suite abandonnés et trahis par ceux-là mêmes qui étaient venus les secourir. Dans ce récit-reportage, certains mots prennent un nouveau sens, comme «relocalisation» ou "examen humanitaire» (un bel euphémisme en l'occurrence); un néologisme apparaît, "dubliné», pour désigner les personnes auxquelles s'applique le règlement de Dublin ${ }^{3}$; mais on découvre surtout un désordre et une inertie interministérielle qui se traduisent par des décisions dérogatoires, arbitraires et incompréhensibles.

Le contexte est celui du départ des troupes françaises à partir de 2012; selon les estimations, ce sont quelque 800 personnes recrutées localement qui ont ravitaillé ces soldats, qui ont cuisiné, conduit et traduit pour eux. Les tarjuman commencent à se faire entendre en manifestant à Kaboul puis à Paris, et une jeune avocate, Caroline Decroix, décide de les défendre bénévolement après avoir lu un article à leur sujet dans le quotidien La Croix en 2015. Avec persévérance, elle parvient, en s'appuyant sur des lois existantes et en mobilisant des collègues bénévoles, à en faire rapatrier quelques-uns; elle se rend en Afghanistan, plaide leur cause auprès de l'ambassadeur de France, va rencontrer ces jeunes interprètes, et parvient finalement à faire aboutir onze demandes sur 140. Les difficultés sont de tous ordres: les interprètes sont anglophones et doivent remplir des documents en français, l'ambassade ne délivre pas de visa malgré les décisions du tribunal en France qui enjoint les autorités à le faire, les ministères sont embarrassés et se transmettent le dossier sans prendre de décisions concertées et cohérentes, et la peur liée à la «crise migratoire» vient renforcer l'inaction. Enfin, le cynisme de certains officiels fait frémir.

À une avocate qui défend les tarjuman et demande à un haut gradé "Comment l'armée française pourra-t-elle recruter avec cette réputation?», celui-ci répond: "Mais comment voulez-vous qu'ils le sachent ${ }^{4}$ ? $\gg$ En d'autres termes, s'il y a d'autres opérations ailleurs, ils n'auront aucun moyen de se contacter, nous pouvons donc continuer ainsi.

3. En vertu de ce texte (qui s'applique dans l'ensemble des pays de l'Union européenne, la Norvège, la Suisse et le Liechtenstein), une demande d'asile ne peut être examinée que par un seul pays européen. II peut s'agir de l'État responsable où réside en tant que réfugié ou demandeur d'asile un membre de la famille du demandeur; l'État qui a délivré au demandeur d'asile un permis de séjour ou un visa toujours en cours de validité; l'État dont le demandeur d'asile a franchi illégalement les frontières. Voir https://ofpra.gouv.fr/ glossaire?lettre=D

4. Brice Andlaver et Quentin Müller, Tarjuman, op. cit., p. 169-170. 
À l'été 2015, l'association parvient à faire examiner 252 dossiers, mais seuls 101 sont acceptés. Parmi les refusés se trouvaient des interprètes ayant travaillé plusieurs années pour l'armée française, mais, les décisions de refus n'étant pas motivées, il est impossible de faire appel. Malgré les maigres victoires, l'association des interprètes afghans poursuit son travail sans relâche.

Alors certains interprètes déboutés décident de partir, empruntent les routes de la migration, finissent par dormir dans un square parisien et déposent un dossier à l'Office français de protection des réfugiés et apatrides (OFPRA) pour pouvoir bénéficier du statut de réfugié. Quelques officiers de l'armée française se sont émus de ce terrible sort et ont cherché à retrouver leur tarjuman. Certains acceptent courageusement de témoigner sous couvert de l'anonymat et se dévouent totalement à une cause qui est devenue la leur, au risque de perdre leur place dans l'armée: "Le seul danger serait que je perde mon boulot. C'est un danger qui est largement surmontable ${ }^{5}$.»

D'autres récits émouvants témoignent des liens d'amitié qui se tissent au fil des mois entre les tarjuman et les familles ou les populations des villes et des villages où ils résident, comme à Laon où l'ancien maire a organisé l'accueil de 26 tarjuman et de leurs familles. Lorsqu'ils arrivent en France dans le cadre du rapatriement (la relocalisation), les autorités ont dans l'ensemble prévu ce qui était indispensable au quotidien; ensuite, les tarjuman s'insèrent dans la société par le biais d'une formation, d'un emploi, d'études universitaires - preuve s'il en était de leur "capacité d'intégration», le fameux critère fourre-tout et bien vague brandi par les autorités françaises.

En tant qu'acteurs, victimes et témoins de ces imbroglios administratifs frustrants, ces jeunes, déprimés, tristes, séparés parfois de leurs épouses et de leurs enfants dans de terribles circonstances, ne manifestent pas de rancœur; ils forcent l'admiration.

Le livre s'achève sur une comparaison entre les États occidentaux présents en Afghanistan: États-Unis, Grande-Bretagne, Allemagne, Espagne, etc. Chaque pays a plus ou moins mis en place des procédures de rapatriement, parfois sous l'effet de campagnes menées par des organisations non gouvernementales 
et les médias. Force est de constater qu'en France, la mobilisation a été faible; sans le travail mené par l'association des interprètes afghans de l'armée française et sa vice-présidente, par François Sureau, auteur de la préface de l'ouvrage, et par quelques journalistes, le nombre de tarjuman décédés serait aujourd'hui bien plus élevé. Heureusement, depuis la parution de ce livre, le Conseil d'État a rendu le 1er février 2019 une décision obligeant l'État français à apporter la protection fonctionnelle à ses interprètes. À suivre...

Brice Andlaver et Quentin Müller, Tarjuman. Enquête sur une trahison française, Paris, Bayard éditions, 2009. 